DN memory B cells

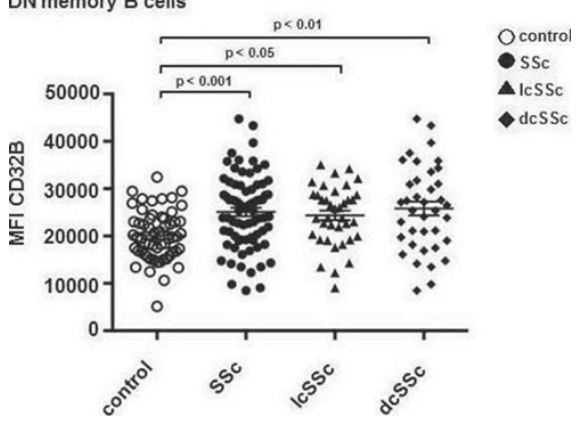

Conclusions: Our results suggest that SSc B cells exhibit compensatory increases in the expression of Fc $\gamma$ RIIB in order to suppress the abnormal activation of $B$ cells, and the expression of $\mathrm{Fc}_{\mathrm{C}} \mathrm{R}$ IIIB may be an indicator of the clinical severity of SSc.

Disclosure of Interest: None declared

DOI: 10.1136/annrheumdis-2017-eular.2064

\section{AB1170 PREVALENCE OF ANTI-CARP ANTIBODIES IN PATIENTS WITH PRIMARY SJÖGREN'S SYNDROME: ASSOCIATION WITH CLINICAL, SEROLOGICAL AND HISTOLOGICAL ASPECTS}

S. Colafrancesco ${ }^{1}$, G. Piacarelli ${ }^{1}$, A. Pecani ${ }^{1}$, T. Colasanti ${ }^{1}$, F. Spinelli ${ }^{1}$, C. Alessandri ${ }^{1}$, C. Barbati ${ }^{1}$, M. Vomero ${ }^{1}$, B. Cerbelli ${ }^{2}$, R. Priori ${ }^{1}$, G. Valesini ${ }^{1}$. ${ }^{1}$ Dipartimento di medicina interna e specialità mediche; ${ }^{2}$ Dipartimento di radiologia, Oncologia e Scienze Patologiche, Sapienza Univeristy of Rome, Rome, Italy

Background: The presence of antibodies against carbamylated peptides (antiCarP) has been associated with increased disease activity and severe joint damage in rheumatoid arthritis. Our group has demonstrated their presence also in other inflammatory conditions with a high prevalence in Sjogren's Syndrome (SS) $(14 / 45,31.1 \%)^{1}$. There is only one study up to now investigating anti-CarP in SS demonstrating a prevalence of these antibodies in $27 \%$ of cases and an association with the presence of germinal centres (GCs) ${ }^{2}$. Thus, these antibodies have been proposed as a new tool for identifying SS patients with a more aggressive disease.

Objectives: To confirm the presence of anti-CarP antibodies in a large monocentric cohort of patients with SS and investigate their association with clinical, serological and histological features.

Methods: Serum samples from consecutive patients with SS (AECC criteria) were collected and stored at $-20^{\circ}$. Anti-CarP antibodies were detected by a modified solid-phase "home-made" ELISA ${ }^{1}$. The mean +3 times SD was used as cut-off. Minor paraffin embedded salivary glands were stained by $\mathrm{H} \& \mathrm{E}$ and $\mathrm{IHC}$ using lymphocytes T and B markers [anti-CD3, anti-CD20 (DAKO)]. GCs presence was defined by $\mathrm{H} \& \mathrm{E}$ and confirmed by identification of follicular dendritic cells (antiCD21, DAKO). Images were analysed as follows: focus score (FS) calculation, mean foci area, presence of segregated foci (SF), GCs and lymphoepithelial lesions (LELs).

Results: Clinical and laboratory features of SS patients are shown in table. Serum anti-CarP were detected in $30 / 104$ patients $(28.8 \%)$ without association with any clinical or serological feature (Fisher's exact test). Positive patients were more likely to present $S F(P=0.024)$. No association was found with the presence of $G C s$ or LELs. Anti-CarP titre correlated with the FS $(P=0.045, r=0.304)$, the number of foci $(P=0.008, r=0.347)$, mean foci area $(P=0.028, r=)$ and the percentage of SF $(P=0.046, r=0.331)$ (Spearman's test). Prevalence of anti-CarP was higher in patients with arthritis [7/15 (46.6\%)] than those without ([23/89 (25.8\%)] ( $p>0.05)$.

\begin{tabular}{ll}
\hline Clinical features & Number $(\%)$ \\
Sex (M/F) & $5 / 99$ \\
Age at diagnosis (mean士SD, years) & $53 \pm 11.7$ \\
Xerophthalmia & $93 / 104(89.4)$ \\
Xerostomia & $97 / 104(93.2)$ \\
Glandular swelling & $31 / 104(29.8)$ \\
Arthritis & $15 / 104(14.4)$ \\
Lymphoma & $3 / 104(2.8)$ \\
Laboratory features & \\
ANA & \\
Anti-Ro/SSA & $88 / 104(84.6)$ \\
Anti-La/SSB & $54 / 104(51.9)$ \\
Hypergammaglobulinemia & $42 / 104(40.3)$ \\
Rheumatoidfactor & $28 / 104(26.9)$ \\
Leucopenia & $38 / 104(36.5)$ \\
Hypocomplementemia & $21 / 104(20.1)$ \\
Monoclonal component & $9 / 104(8.6)$ \\
Cryoglobulinemia & $8 / 104(7.6)$ \\
\hline
\end{tabular}

Mean anti-CarP titre was higher in patients with arthritis compared to those without (322.3 $\pm 173.8 \mathrm{aU} / \mathrm{ml}$ vs $279.5 \pm 171.1, \mathrm{P}=0.004$, respectively).

Conclusions: This is the largest cohort of SS patients screened for anti-CarP so far. Our results show a prevalence of anti-Carp antibodies in agreement with the literature; however, no association was found with any clinical or serological aspect. Anti-CarP do not seem to be associated with histological features predictive of lymphoma, i.e. CGs and LELs. Nonetheless, considering the titre correlation with the FS, mean foci area and percentage of segregation, higher serum levels of anti-CarP may reflect a severe tissue inflammation more prone to form organized infiltrates. This finding, in association with the evidence of higher levels in patients with arthritis, may support the idea that these antibodies are useful to measure the severity of systemic inflammation.

References:

[1] Pecani A et al. Arthritis Res Ther. 2016 25;18(1):276.

[2] Bergum B et al. Ann Rheum Dis. 2016;75(8):1494-500.

Disclosure of Interest: None declared

DOI: 10.1136/annrheumdis-2017-eular.5774

\section{AB1171 ARTICULAR AND EXTRA-ARTICULAR DAMAGE INDEX ASSESSMENT IN JUVENILE IDIOPATHIC ARTHRITIS PATIENTS}

S.M. El-Gamal, E.A.K. Elewa, M.M. Ashour. Rheumatology and Rehabilitation, Zagazig University Hospitals, Zagazig, Egypt

Background: Juvenile Idiopathic Arthritis is a broad term used to describe several different forms of chronic arthritis in children. Variable assessment tools can be used for assessment of JIA disease activity. JADI is composed of 2 parts (Viola et al., 2005).

Objectives: Assessment of the articular and extraarticular damage index in juvenile idiopathic arthritis patients.

Methods: This study was carried out on 60 JIA patients. Patients who had inflamed synovia related to trauma or malignant disease, septic arthritis, bone diseases, as dysplasia or osteomyelitis were excluded. Clinical assessment: sex, age at disease onset, JIA category, educational level, loss of school years and previous use of systemic corticosteroid and second-line drug therapies. Local examination: Number of swollen joints, joints with pain on movement/tenderness, joints with limited range of motion, joints with active arthritis were recorded for every patient. Disease activity: was measured by using the (JADAS-27). Functional ability: was assessed by (CHAQ). Laboratory assessment: included ESR and CRP. Radiographic assessment: scored according to the adapted Sharp/van der Heijde score. Damage assessment: was assessed using the Juvenile Arthritis Damage Index.The (JADI-A) and (JADI-E).

Results: Patient characteristics: 6 had systemic onset, 29 had polyarthritis, 14 extended oligoarthritis, 11 had persistant oligoarthritis and none of them had psoriatic arthritis. 38 females and 22 males (56.7\%) percent of patients lost some years of education ranging from $0-3$ years. Patients in remession were very few 5 patients only. According to the C-HAQ score (13.3\%) of patients had no disability $(11.7 \%)$ mild disability $(41.6 \%)$ moderate disability and (33.3\%)severe disability. $60 \%$ patients had articular damage and $35 \%$ patients had extraarticular damage. The wrist was the most frequently damaged joint.The growth failure, pubertal delay and leg length discrepancy were the most frequently reported extraarticular items. Correlation of JADI with other disease variables: showed that JADI-A is correlated with physician's global assessment, $\mathrm{CHAQ}$, radiological damage.

Conclusions: Ours is the first study that has used JADI to assess outcome in patients with JIA in Egypt. JADI has a good correlation with traditional outcome measures in JIA and may be a good tool to be used in clinical practice and is likely to increase current understanding of the natural history of the disease.

[1] Singh G., Arthreya B.H., Fries J.F., et al. (1994): Measurement of health status in children with juvenile rheumatoid arthritis. Arthritis Rheum.; 37 (12) 1761-769.

[2] Viola S., Felici E., Magni-Manzoni S., et al. (2005): Development and validation of a clinical index for assessment of long term damage in juvenile idiopathic arthritis. Arthritis \& Rheumatism ;52(7):2092-2102.

[3] Ravelli A. and Martini A. (2007): Juvenile idiopathic arthritis. Lancet 369:76778.

[4] Boros C. (2010): Juvenile idiopathic arthritis. Australian family physician ;39(9):630-636.

[5] Tanner JM, Davies PS 1985.Clinical longitudinal standards for height and height velocity for North American children. J Pediatr 107:317-329.

Acknowledgements: First of all, thanks to Gracious Allah. I would like to express my profound gratitude and appreciation to Prof. Dr. Enass Abdel Kader Elewa and to Prof. Dr. Mahmoud Moustafa Ashour for support and supervision.

Disclosure of Interest: None declared

DOI: 10.1136/annrheumdis-2017-eular.6707 